\title{
Cylindrical battery ingested by a 1-year-old baby - does the voltage matter?
}

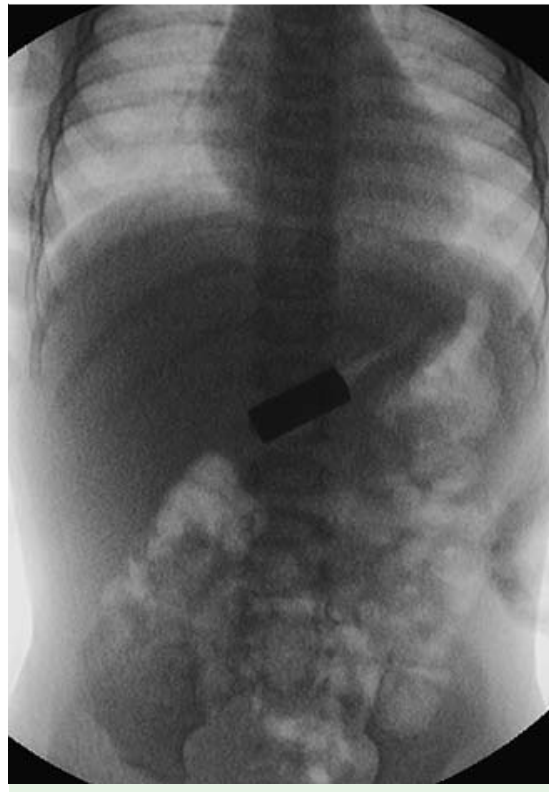

Fig. 1 Radiograph showing a cylindrical battery in the stomach of a 1-year-old child.

The ingestion of a button-type battery cell by a child is an indication for urgent extraction (within 2 hours) if it has impacted in the esophagus because of the risks of major or even fatal complications, such as perforation and bleeding. In contrast, the ingestion of a cylindrical-type battery that passes into the stomach is not an indication for acute extraction as long as it is not causing symptoms. A follow-up radiograph after a 4-day interval is considered to be sufficient $[1,2]$.

We were asked to extract a cylindrical battery from the stomach of a 12-monthold asymptomatic girl approximately 26 hours after she had been witnessed ingesting it ( Fig.1). The procedure was performed with the patient under general anesthesia, using a gastroscope (GIF Q180; Olympus Optical Co., Tokyo, Japan) with a polypectomy snare. During the endoscopy, two ulcers, approximately $10-15 \mathrm{~mm}$ in diameter, were found on the front and back walls of the stomach ( $\mathbf{F i g . 2}$ ), together with several small erosions on the greater curvature ( Video 1 ). The battery was identified as a type A23.
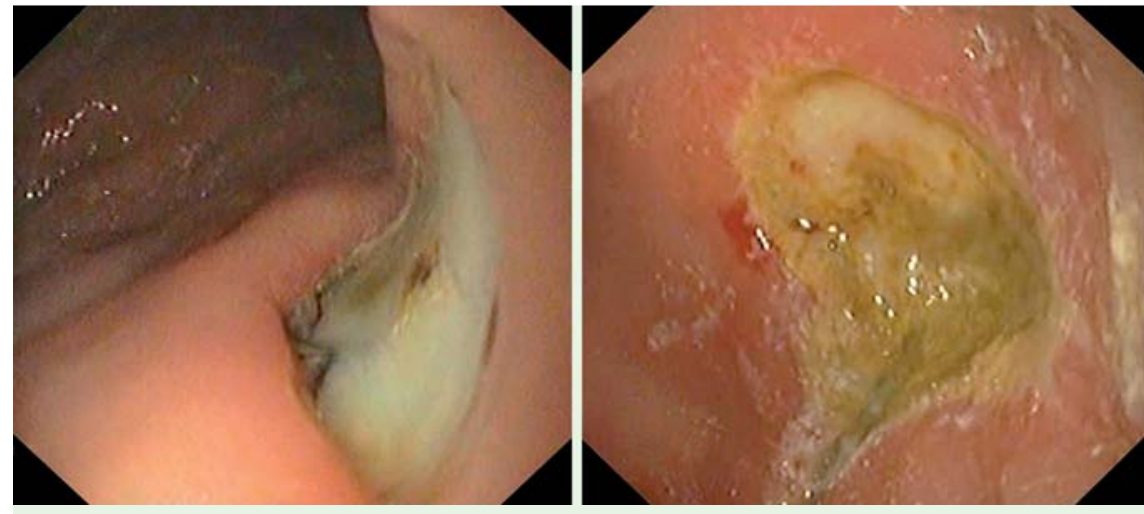

Fig. 2 Endoscopic images of the two ulcers found on the front and back walls of the stomach.

A proton pump inhibitor was prescribed and ampicillin/sulbactam was added for complicating nasopharyngitis; otherwise the child's subsequent course was uneventful.

The supposed mechanism of battery-induced injury consists of (in order of importance): generation of an external electrolytic current that hydrolyses tissue fluids and produces hydroxide at the negative pole; leakage of alkaline electrolyte; and physical pressure [3].

A type-A23 battery consists of eight button alkaline cells (based on a manganese dioxide chemical system) bound together to form a cylinder that is $10 \mathrm{~mm}$ in diameter and $28 \mathrm{~mm}$ long and gives off a voltage as high as $12 \mathrm{~V}$, as opposed to $1.5 \mathrm{~V}$ in more common and similar sized microbatteries (type AAA; $10 \times 44 \mathrm{~mm}$ ) [4].

We propose that in terms of the indication and timing of an endoscopic extraction of a cylindrical battery ingested by a child, the particular type and voltage of the battery should be considered, with particular regard being paid to the higher voltage types, such as A23 or A27. Potentially dangerous gastrointestinal tract damage could therefore be prevented.

\section{Endoscopy_UCTN_Code_CCL_1AB_2AF}

\section{Competing interests: None}

\section{Video 1}

Endoscopic extraction of a cylindrical battery. Ulcers and erosions were observed in the stomach and a type-A23 battery was extracted using a polypectomy snare.

Jiri Cyrany ${ }^{1,2}$, Jan Melek ${ }^{2,3}$, Petr Dedek ${ }^{2,3}$, Jan Toms ${ }^{1,2}$, Stanislav Rejchrt ${ }^{1,2}$

1 2nd Department of Internal Medicine Gastroenterology, University Hospital, Hradec Kralove, Czech Republic

${ }^{2}$ Charles University in Prague, Faculty of Medicine in Hradec Kralove, Hradec Kralove, Czech Republic

${ }^{3}$ Department of Pediatrics, University Hospital, Hradec Kralove, Czech Republic

\section{Acknowledgments}

$\nabla$

Supported by project PRVOUK P37-08.

\section{References}

1 Battery Ingestion Triage and Treatment Guideline. In: National Capital Poison Center [online] 2009 updated 7 May 2013. Accessed: 15 July 2014. Available from: http:// www.poison.org/battery/guideline.asp

2 Sinclair K, Hill ID. Button and cylindrical battery ingestion. In: UpToDate.com [online] 2013, updated 24 October 2013. Accessed: 15 July 2014. Available from: http://www. uptodate.com/contents/button-and-cylindrical-battery-ingestion?topicKey= 
3 Litovitz T, Whitaker N, Clark L et al. Emerging battery-ingestion hazard: clinical implications. Pediatrics 2010; 125: 1168-1177

4 Energizer Holdings, Inc. Product datasheet Energizer A23 [online]. Energizer Holdings Inc. 2000-2014. Accessed: 15 July 2014. Available from: http://data.energizer.com/ PDFs/a23.pdf

\section{Bibliography}

Dol http://dx.doi.org/

10.1055/s-0034-1377772

Endoscopy 2014; 46: E543-E544

(c) Georg Thieme Verlag KG

Stuttgart · New York

ISSN 0013-726X
Corresponding author

\section{Jiri Cyrany, MD}

2nd Department of Internal Medicine Gastroenterology

University Hospital Hradec Kralove

Sokolska 581

50005 Hradec Kralove

Czech Republic

Fax: +420-495-834785

jiri.cyrany@fnhk.cz 